\title{
CONCEPÇÕES DE EDUCAÇÃO AMBIENTAL NO CURSO DE AGRONOMIA DE UMA UNIVERSIDADE PÚBLICA FEDERAL DO NORDESTE DO BRASIL
}

\author{
Cirdes Nunes Moreira ${ }^{1}$, Monica Lopes Folena Araújo ${ }^{2}$
}

\author{
${ }^{1}$ Doutorando no Programa de Pós-Graduação em Ensino das Ciências - PPGEC da Universidade Federal Rural de Pernambuco - UFRPE. \\ ${ }^{2}$ Docente do Departamento de Educação - DEd e do Programa de Pós-Graduação em Ensino das Ciências - PPGEC da Universidade Federal Rural de \\ Pernambuco - UFRPE. \\ * Autor para correspondência: cirdesnm@gmail.com
}

Recebido em 06 de novembro de 2017. Aceito em 19 de maio de 2018. Publicado em 20 de junho de 2018.

REsumo - Neste trabalho, seguindo procedimentos de Análise de Conteúdo, foram investigadas as concepções de Educação Ambiental no Projeto Pedagógico de Curso e em entrevistas realizadas junto à direção do departamento acadêmico e coordenação do Curso de Agronomia de uma universidade pública federal situada na região Nordeste do Brasil. A pesquisa mostrou indícios de uma Educação Ambiental conservadora, desvinculada da natureza social, cultural e política. As abordagens de natureza social estão restritas a cinco componentes curriculares que totalizam $6,4 \%$ da carga horária total do curso. A observação participante nas aulas, investigando a prática docente, poderá revelar com maior clareza, no prosseguimento desta pesquisa, que concepções de Educação Ambiental estão permeando a formação dos Engenheiros Agrônomos diplomados pela instituição.

Palavras-chave: Educação Ambiental; Agronomla; Análise de Conteúdo.

CONCEPTIONS OF ENVIRONMENTAL EDUCATION IN THE AGRONOMY COURSE OF A FEDERAL PUBLIC UNIVERSITY IN NORTHEASTERN BRAZIL

Aвstract - Following the content analysis procedures, the concepts of environmental education in educational policy project and in the interviews conducted with the direction of the academic department and coordination of agronomy course of a public university in northeastern Brazil were investigated in this work. Signs of a conservative environmental education, independent of the social, cultural and political nature, were observed in the research. The social nature approaches are restricted to five curricular components totaling $6.4 \%$ of the total course hours. The participant observation in the classes, investigating the teaching practice, could reveal more clearly, in the continuation of this research, that the ideas of environmental education are permeating the formation of agricultural engineers graduated by the institution.

Keywords: Entironmental EDUCATION; Agronomy; CONTENT ANALYSis.

ConCEPCiONES de EDUCACIÓN AMBIENTAL EN EL CURSO DE AGRONOMía EN UNA UNIVERSIDAD PÚBLICA FEDERAL DEL NORDESTE DE BRASIL

Resumen - En este estudio, siguiendo procedimientos de Análisis de Contenido, se investigaron las concepciones de Educación Ambiental en el Proyecto Pedagógico de Curso y en entrevistas realizadas en conjunto con la dirección del departamento académico y coordinación del Curso de Agronomía de una universidad pública federal en la región Nordeste de Brasil. La investigación mostró indicios de una educación ambiental conservadora, desvinculada de la naturaleza social, cultural y política. Los enfoques de naturaleza social están restringidos a cinco componentes curriculares que totalizan el 6,4 \% de la carga horaria total del curso. La observación participante en las clases, investigando la práctica docente, podrá revelar con mayor claridad, en la continuación de esta investigación, cuales concepciones de Educación Ambiental están 
permeando la formación de los Ingenieros Agrónomos diplomados por la institución.

Palabras clave: Educación Ambiental; Agronomía; Análisis de Contenido.

\section{INTRODUÇÃO}

Esta pesquisa objetivou identificar as concepções de Educação Ambiental (EA) em entrevistas realizadas com a direção do departamento acadêmico e coordenação do Curso de Agronomia de uma universidade pública federal situada na região Nordeste do Brasil, bem como no Projeto Pedagógico do Curso (PPC), mapeando as concepções de EA nos componentes curriculares obrigatórios e optativos, analisando indícios que o documento e entrevistas apresentam de valorização da EA enquanto ação educativa interdisciplinar, articuladora do conjunto de saberes, que vise contribuir para a formação de atitudes e sensibilidades ambientais que privilegiem uma visão complexa do meio ambiente, onde a natureza integra uma rede de relações não apenas naturais, mas também sociais e culturais, conforme preceitua Carvalho (2006).

O Curso de Agronomia estudado, de evidenciada importância para o Estado e para a região Nordeste, é oferecido desde o ano de 1914 na sede da sua instituição, situada na capital e, a partir do ano de 2005, com a recente política de expansão universitária, passou a ser oferecido também em dois municípios interioranos, localizados nas regiões Agreste e Sertão do Estado, disponibilizando anualmente um total de 240 vagas, sendo 120 na sede e 60 em cada unidade do interior. O período desta expansão geográfica coincide com a conclusão, em 2006, do PPC analisado e que abrange as três unidades acadêmicas.

Os agrônomos, no exercício da profissão, lidam diretamente com a organização de diferentes processos de produção agropecuária voltados ao abastecimento de alimentos, fibras e outros produtos, os quais devem se caracterizar pelos devidos cuidados com o ambiente, visando atender aos anseios da sociedade, cada vez mais presentes, no que concerne à sustentabilidade. No desenvolvimento de suas atividades, devem ser multiplicadores de uma visão crítica-reflexiva, política, ética, capaz de compreender os contextos históricos e culturais, assim influindo positivamente sobre a qualidade de vida das pessoas com quem trabalham diretamente e igualmente da sociedade como um todo.

Nas atividades dos agrônomos junto aos diferentes atores no campo, sua formação universitária e concepções sobre EA parecem influenciar suas abordagens e práticas, sobretudo junto àqueles segmentos mais fragilizados, que teriam ocupado lugar não privilegiado no contexto dos currículos, tecnologias, políticas públicas e processos produtivos, muitas vezes direcionados que são à lógica do agronegócio, fortalecida a partir da segunda metade do século XX, com a modernização da agricultura. Esta, influenciando os currículos e os processos tecnológicos, privilegiou o viés tecnicista, a fragmentação do conhecimento e a tendência à visão simplificada diante da complexidade que envolve os problemas e suas soluções, cujos alcances se processaram em níveis desiguais, tanto em relação às regiões do país, quanto aos diferentes grupos sociais no campo.

Desta maneira, as questões ambientais, que têm sido alvo de reflexões e debates no cenário mundial, também guardam estreita relação com as atividades dos agrônomos, decorrentes do impacto das suas intervenções sobre a natureza que, tendo o homem como parte dela, devem valorizar, como preceitos fundamentais, a cidadania, os projetos sociais emancipatórios e transformadores, a perspectiva da construção de uma sociedade ecologicamente prudente, socialmente justa, culturalmente diversa, politicamente atuante e economicamente viável, aspectos destacados por Layrargues (2012), como importantes para qualificar as identidades, intencionalidades e os 
sentidos das ações de EA.

Assim, a perspectiva da EA vem se tornando um campo de interesse de pesquisas, também na formação dos agrônomos, por diferentes autores. Souza (2006), em sua dissertação apresentada ao Mestrado em Educação da Universidade Federal de Santa Maria (UFSM), analisou o cenário de elaboração do PPC do Curso de Agronomia daquela universidade, no que tange às possibilidades e dificuldades de inserção da EA. Grings (2009), em sua tese defendida no Doutorado em Educação da Universidade Federal do Rio Grande do Sul (UFRGS), investigou o espaço formal e significados atribuídos à EA em políticas públicas e nos cursos de graduação em Engenharia Agronômica na UFRGS e UFSM. Mais recentemente, Araújo e Oliveira (2015), também desenvolveram estudos envolvendo a EA no Curso de Agronomia, desta feita no âmbito da Universidade Federal de Sergipe (UFS).

A compreensão desta problemática envolve outros olhares e pressupostos e não apenas os enfoques técnicos que parecem ter permeado tradicionalmente os currículos no país. A relação do exercício profissional dos agrônomos, lidando com as questões de natureza tecnológica e os recursos naturais e socioeconômicos, são inquietações que por si só nos motivam para a realização do presente estudo, no âmbito da instituição estudada que tem na Agronomia, um dos seus cursos fundadores.

A seguir são apresentados, a título de fundamentação, alguns aspectos relacionados ao caráter político que permeia os PPC, onde os interesses e forças que neles gravitam, terminam por delimitar pedagogicamente as ações educativas para que os cursos cumpram seus propósitos e intencionalidades, onde a EA integrada, contínua, permanente, transversal e interdisciplinar tem se tornado um direcionamento estratégico, de perspectiva transformadora, que valoriza a formação cidadã, quase ausente nos currículos tradicionais, de abordagem conservadora e fragmentada.

Nas pesquisas relacionadas ao funcionamento e oferta dos cursos superiores, a análise de documentos institucionais tem contribuído para o conhecimento inicial das proposições em relação aos mesmos, do ponto de vista da sua concepção. Nesse contexto, Grings (2009) chama atenção para o caráter político dos PPC, porque propõem e reveem os fins do curso ou da instituição, as justificativas das opções por determinado currículo, relacionando-se aos compromissos sociopolíticos, os interesses reais e coletivos da população. Do ponto de vista pedagógico, no PPC estão definidas as ações educativas para que os cursos cumpram seus propósitos e intencionalidades.

Em relação ao ensino superior, Gil (2009) chama atenção que o início das atividades do professor universitário se dá com o planejamento do ensino, que envolve o diagnóstico, o planejamento em si, a execução e a avaliação. No nível institucional, o autor também destaca a natureza política, "pois estabelece um compromisso com a formação de um cidadão para um tipo de sociedade" (Gil 2009, p. 97), e pedagógica do planejamento, "pois define os propósitos e a forma de efetivação das ações educativas da escola" (Gil 2009, p. 97). Ainda em relação ao planejamento curricular, segundo Gil (2009), a Lei de Diretrizes e Bases da Educação Nacional LDBEN (Lei no 9.394, de 20 de dezembro de 1996) ampliou a autonomia das instituições de ensino superior na fixação dos seus cursos, desde que em consonância com as Diretrizes Curriculares gerais.

De acordo com Gil (2009, p. 98)

As Diretrizes Curriculares asseguram ampla flexibilidade às diferentes Instituições de Ensino Superior na elaboração de seus currículos, que, dessa forma, passam a dispor de melhores condições para atender às necessidades diferenciais de suas clientelas e às peculiaridades das regiões nas quais se inserem. Isso significa, por outro lado, que necessitam ser mais criativas e responsáveis. 
O PPC, segundo Veiga (1995, p. 14), “é um processo permanente de reflexão e discussão dos problemas da escola, na busca de alternativas viáveis à efetivação de sua intencionalidade”. Para tanto, enquanto processos democráticos de organização do trabalho pedagógico, eles devem buscar direções coletivamente definidas. Neste sentido, a participação torna-se característica fundante nesses processos e como tal, conforme delimita Gandin (1999), ela inclui a distribuição do poder e também a possibilidade de decidir na construção não apenas do "como" ou do "com que" fazer, mas também do "o que" e do "para que" fazer, ou seja, as intencionalidades da instituição de ensino, diante dos diferentes contextos da sociedade na qual está inserida.

Padilha (2001) destaca que o planejamento educacional deve ser contextualizado e responder às marcas e aos valores da sociedade para a qual é realizado; sendo necessária uma participação dialógica entre educadores e educandos. Moacir Gadotti, no prefácio da obra de Padilha (Gadotti 2001), reforça a importância da dialogicidade e participação de todos os envolvidos no processo educativo, para a construção de um projeto educacional que vise à formação cidadã e ao desenvolvimento pleno das gerações atual e futura. Conforme as concepções de Paulo Freire, onde "é decidindo que se aprende a decidir" (Freire 2002, p. 66), as decisões se constituem por um vasto processo que deve privilegiar a dialogicidade, com o envolvimento de todos, especialmente daqueles que executam e, não somente, com pedagogos ou supostos intelectuais.

O estudo do PPC pode oferecer revelações, a respeito de um curso, da instituição ofertante e das intencionalidades na sua concepção. Desta maneira, Araújo (2012b) encontrou indícios importantes para os resultados alcançados pela pesquisa que realizou sobre o quefaz̧er da Educação Ambiental crítico-humanizadora na formação inicial de professores de biologia, ao analisar o Plano de Desenvolvimento Institucional - PDI e o Plano Político Pedagógico Institucional - PPPI da Universidade Federal Rural de Pernambuco (UFRPE) e da Universidade Federal de Pernambuco (UFPE).

O estudo do PDI da UFRPE feito por Araújo (2012b), por exemplo, evidenciou, dentre outras coisas, a importância histórica da instituição para o estado de Pernambuco e região Nordeste, tratando-se de uma universidade voltada para a inovação tecnológica, atendimento dos anseios da sociedade, que desenvolve políticas educacionais e proporciona o desenvolvimento sustentável e o empreendedorismo, com os profissionais egressos levando inovações às áreas rurais, respeitando o meio ambiente.

A análise do PPC também representa uma etapa importante para o conhecimento das concepções que norteiam um referido curso, do ponto de vista da formação de profissionais nele realizada. Ademais, analisá-lo sob a ótica das perspectivas da EA nele presentes, representa uma iniciativa que pode revelar aspectos relevantes, dada à importância da temática no contexto atual, em relação aos investimentos feitos nas universidades públicas e seu retorno, diante das demandas da sociedade.

Nesse contexto, a valorização da perspectiva cidadã na formação dos agrônomos pode ser entendida como uma "troca de lentes", utilizando-se da metáfora pensada por Isabel Cristina de Moura Carvalho (Carvalho 2006, p. 37), para explicar a superação entre a EA marcada pela tradição naturalista, para uma visão socioambiental que permita ver as relações de interação permanentes entre a vida humana e a vida biológica da natureza. De forma análoga, para os agrônomos, considerando o grande potencial político que tem a profissão, em relação às inovações e construção da sustentabilidade da sociedade, também se faz necessário privilegiar, na sua formação, perspectivas que deem lugar a uma visão complexa do ambiente, que possibilitem, para além de uma formação com viés que favoreça o tecnicismo, problematizar a natureza como uma rede de relações não apenas naturais, mas também sociais e culturais, conforme preconiza Carvalho (2006) quando propõe a formação de "sujeitos 
ecológicos".

Não é demais registrar que desde o ano de 1972, com a realização da I Conferência Internacional sobre Meio Ambiente, em Estocolmo, a EA vem se tornando objeto de políticas públicas no Brasil e no mundo. A institucionalização no âmbito federal em 1973, com a criação da Secretaria Especial do Meio Ambiente (SEMA), a Constituição Federal de 1988 que estabelece a qualidade ambiental como direito e dever de todos e a Política Nacional de Meio Ambiente (PNMA), de 1981, que tornou necessária a inclusão da EA em todos os níveis de ensino, são marcos importantes nesta trajetória que teve a EA instituída no Brasil pela Lei 9.795 de 27 de abril de 1999 (Brasil 1999).

Da forma como está definida, a EA deve ser desenvolvida como uma prática educativa integrada, contínua, permanente, transversal e interdisciplinar, e não como disciplina específica incluída nos currículos escolares. Trata-se de um componente essencial e permanente da educação no país, que deve estar presente, de forma articulada em todos os níveis e modalidades do processo educativo, seja ele de caráter formal, seja não formal (Brasil 1999).

Layrargues (2004) chama atenção que o termo "Educação Ambiental" abrange diferentes classificações e denominações que explicitam e preenchem de sentido às práticas e reflexões pedagógicas relacionadas às questões ambientais. Araújo (2012a) também destaca a pertinência a respeito do entendimento das diferentes tipologias que garantem o reconhecimento das identidades da EA que vêm despontando no Brasil e no mundo. Assim, na análise das concepções de EA, as mesmas podem ser sistematizadas conforme seus diferentes tipos em: conservadora, crítica, transformadora, ecopedagogia, alfabetização ecológica, delimitados em Layrargues (2004) e ainda, crítico-humanizadora, conforme os estudos realizados por Araújo (2012b).

Após esta fundamentação serão apresentados o percurso metodológico, a análise de conteúdo do PPC e das entrevistas realizadas com a coordenação e direção do departamento acadêmico do curso analisado, as considerações finais e as referências.

\section{Material e métodos}

O presente trabalho teve como locus de estudo o Curso de Agronomia de uma universidade pública federal localizada na Região Nordeste do Brasil. Do ponto de vista metodológico, este estudo consistiu na aplicação de entrevistas semiestruturadas com a direção do departamento acadêmico e coordenação do curso, bem como na pesquisa documental envolvendo o Projeto Pedagógico do Curso (PPC) de Agronomia da referida instituição, cuja identidade optamos por preservar, tratando-a como "instituição estudada" e o PPC como "PPC da instituição estudada" (PPC 2006). O PPC e as entrevistas foram submetidas à Análise de Conteúdo, conforme Bardin (1994). Tratando-se de uma pesquisa de natureza qualitativa, para o alcance dos objetivos definidos, a utilização da Análise de Conteúdo se desenvolveu em três fases: pré-análise; exploração do material; e, tratamento dos resultados, inferência e interpretação (Bardin 1994, p. 121).

A pré-análise, que é a "fase de organização propriamente dita”, correspondeu a um período de intuições, operacionalização e sistematização das ideias iniciais. Fizemos a primeira leitura, caracterizada como flutuante, a partir da qual estabelecemos um contato inicial com o documento e entrevistas transcritas, buscando conhecer sua estrutura e formar as primeiras impressões sobre os mesmos. Novas leituras buscaram identificar, a partir da demarcação de algumas partes do texto, que indícios poderiam trazer que nos permitissem associações com 
concepções de EA.

Neste primeiro momento, buscamos demarcar no texto palavras (e suas derivações) tais como: ambiente, educação, natureza, homem, humano, criticidade, pedagogia, ecologia, cidadania, sustentabilidade etc. Buscávamos suas ocorrências, demarcávamos os seus contextos (já que muitas vezes elas sozinhas não guardavam nenhuma relação com o interesse desta pesquisa, passando a serem descartadas), que iriam dar origem às unidades de registro submetidas à análise, por categorização semântica.

Outro exercício realizado foi a detecção da frequência das palavras no documento (PPC 2006), através da implementação de um algoritmo, cuja programação definiu como procedimentos: leitura do texto; remoção de toda e qualquer tabulação, quebra de linha, pontuação e caracteres especiais (\%, \, “” etc.); separação do texto por espaços, gerando uma lista de palavras; para cada palavra o algoritmo força que ela fique em "caixa baixa", eliminando assim a diferenciação entre iniciais maiúsculas e minúsculas; verifica-se se a palavra é um numeral; se a palavra não for um numeral ela é adicionada a uma lista de frequência, desconsiderando gênero e número; e, gera-se, como resultado final, uma lista que prioriza a ordem alfabética, com indicação do número de vezes que cada palavra aparece no texto.

Logicamente, entendemos que no caso específico do presente estudo, as palavras unicamente não devem ser tomadas como unidade de análise, entretanto avaliamos que, para fins das inferências iniciais, a análise da frequência de alguns termos, bem como a ausência de outros, já poderia nos oferecer algumas pistas para a análise de conteúdo que foi realizada, levando em consideração os contextos e respectivos sentidos que norteiam o documento, conforme será apresentado adiante.

Complementando a coleta de dados para esta análise, e visando elucidar melhor as concepções de EA que estão norteando o Curso de Agronomia da instituição estudada, foram realizadas duas entrevistas semiestruturadas, envolvendo a Coordenação do Curso e a Direção do Departamento de Agronomia da instituição, tendo como eixos as três questões norteadoras seguintes: (1) Qual a sua concepção sobre Educação Ambiental?, (2) Como você avalia a relação da Educação Ambiental com o exercício da Agronomia?, e (3) Como vem sendo abordada a Educação Ambiental no Curso de Agronomia da instituição?

As entrevistas foram gravadas e seus arquivos de áudio, formato WAV (WAVEform audio format), com 302,8 MB (megabyte), armazenados com os autores, foram transcritos, gerando dois arquivos de texto (codificados como “e1” e “e2”) que foram submetidos à Análise de Conteúdo, conforme Bardin (1994).

Das leituras do PPC (2006) e das duas entrevistas, foram destacados fragmentos dos textos que deram origem às unidades de registro para a análise realizada. A unidade de registro, segundo Bardin (1994, p. 130) "é a unidade de significação a codificar e corresponde ao segmento de conteúdo a considerar como unidade de base, visando a categorização e análise frequencial”. Trataram-se, conforme Bardin igualmente estabelece, de unidades de natureza e dimensões muito variáveis e, no caso da análise realizada, os recortes foram executados a nível semântico, com um total de 97 unidades de registro.

A análise dos contextos realizada posteriormente permitiu encontrar temas e descobrir alguns núcleos de sentido que compõem as comunicações analisadas, nas quais, sua presença, frequência de aparição e ainda sua ordem podem representar significados para os objetivos da análise empreendida.

Bardin (1994) chama atenção para o fato que a ausência de elementos pode também, em alguns casos, veicular um sentido, daí, para certos objetivos de análise, a ausência constitui a variável importante (Bardin 1994, p. 134). A autora evidencia ainda a pertinência de considerar a ordem de aparição das unidades de registro 
nas entrevistas ou relatos, conferindo significado de maior importância no quadro de inferências para aqueles elementos que precedem outros (Bardin 1994, p. 138).

O tema, enquanto unidade de registro, corresponde a uma regra de recorte (do sentido e não da forma), sendo geralmente utilizado para estudar motivações de opiniões, atitudes, valores, crenças, tendências etc. (Bardin 1994), portanto perfeitamente aplicável à análise em tela.

As respostas obtidas, durante a aplicação das entrevistas, foram igualmente submetidas à Análise de Conteúdo, visando inferir em que tipologias de EA se enquadram as concepções destacadas pelos entrevistados, em relação às identidades de EA sistematizadas por Layrargues (2004) e Araújo (2012b). As respostas a questões abertas em entrevistas, segundo Bardin (1994, p. 131) "podem ser, e são frequentemente, analisadas tendo o tema como base".

Assim, todas as unidades de registro foram submetidas ao processo de codificação, visando seu agrupamento em categorias, possibilitando a compreensão da significação exata daquelas unidades de registro, contextualizando-as para que se possa finalmente inferir os verdadeiros sentidos que elas expressam e, no seu conjunto, quais as ideias centrais dos documentos analisados, que pudessem responder à questão que norteia o problema desta pesquisa.

Considerando os referenciais teóricos que envolvem a EA e a formação dos agrônomos, o agrupamento por similaridade semântica das unidades de registro resultou na formação de três categorias: concepção de Educação Ambiental (EA), concepção sobre o PPC (P), e perfil do egresso (E); e oito subcategorias: enfoque conservador de EA (c), ênfase no agronegócio (a), abordagem utilitarista (u), abordagem tecnicista ( $\mathrm{t}$ ), abordagem interdisciplinar (i), abordagem ecológica, de meio-ambiente, de sustentabilidade (emas), abordagem regionalista (r), abordagem de sociedade (s).

Além das categorias e subcategorias apresentadas, outras codificações foram estabelecidas, apenas para indicar o local da análise, a fonte dos dados. Assim, codificamos: PPC anterior (v), PPC atual (n), documento (d), entrevista 1 (e1) e entrevista 2 (e2). Em sendo o PPC analisado uma reformulação daquele vigente antes de 2006, no documento e entrevistas identificamos referências em relação a ambos, que julgamos pertinente diferenciálas na fase de codificação, visando assim facilitar a compreensão da análise realizada.

As subcategorias dizem respeito aos sentidos presentes nas unidades de registro, quando analisadas. Aqui cabe registrar que elas podem trazer mais de um sentido, situações nas quais lhes são atribuídos mais de um código. Nestes casos, a ordem de codificação procurou ser fiel à ordem dos sentidos presentes em cada unidade, do mais enfático para o menos enfático.

Para a análise realizada, foram seguidas as regras definidas por Bardin (1994), em relação à exaustividade (leitura e releitura dos dados por diversas vezes), pertinência, exclusividade e representatividade. O processo de análise foi construído sempre buscando estabelecer relações entre o referencial teórico e os núcleos de sentidos emergentes, a partir das leituras do PPC e do conteúdo das entrevistas.

Os trechos demarcados (unidades de registro) dos dois textos (PPC e entrevistas transcritas) foram recortados e, a partir daí agrupados e reagrupados, dando origem aos núcleos de sentido de onde emergiram as categorias e subcategorias da exploração dos textos, cuja análise será apresentada a seguir.

A cada unidade de registro foi atribuído um número, de 1 a 97 (em itálico), o que permite na análise perceber, por exemplo, que "82P.n.e1" diz respeito à unidade de registro de número 82, que trata sobre característica do PPC "P”, atual "n”, presente na entrevista 1 "e1": "o que veio a forçar uma discussão mais rápida, foi que a gente levou 
uma nota no ENADE” (82P.n.e1).

\section{REsultados E Discussão}

O PPC do Curso de Agronomia da instituição estudada foi concluído em setembro de 2006, mesmo ano em que foi publicado o Plano de Desenvolvimento Institucional (PDI) 2006-2010 da instituição. Sua elaboração ficou a cargo da equipe formada por coordenadores do curso da gestão iniciada em 2005 e das duas gestões que a antecederam (1996 a 2003, e 2003 a 2005).

$\mathrm{Na}$ apresentação da referida proposta é assegurado que sua construção "atendeu os ditames da legislação pertinente e das demandas socioeconômicas apresentadas pela sociedade brasileira" (1P.n.d). Para justificar sua necessidade enquanto proposta de reformulação, o PPC apresenta um breve histórico das últimas versões de estrutura curricular para o Curso de Agronomia, concebidas a partir de "um estudo iniciado no final dos anos oitenta" (2P.v.d), contribuindo para o atendimento de "aspirações e demandas do perfil profissional exigido durante os anos 90" (3P.E.v.s.d).

Naquele contexto, o curso teria passado a ser objeto de avaliações que buscavam melhorias, do ponto de vista da formação de novos profissionais, cujas aspirações pessoais iriam para além da perspectiva profissional, vez que buscariam atender também às demandas da sociedade brasileira. A estrutura curricular concebida a partir de então, valorizaria a perspectiva cidadã no projeto de formação, "Novas discussões se desencadearam quando, já sob a responsabilidade do Professor [...], no momento frente à Coordenação do Curso, a grade curricular anterior foi então implementada e sob a qual, encontram-se regidos os estudos e parte da consolidação em cidadania da maioria dos alunos do Curso" (4P.v.s.d).

A nova estrutura curricular é proposta então, no ano de 2006, com o objetivo de flexibilizar o curso, tornando-o menos longo, permitindo a integralização em até quatro anos e meio:

Com a flexibilização planejada para essa nova matriz curricular, a duração do Curso de Agronomia
ficou projetada para cinco anos, ao longo de dez períodos semestrais, perfazendo uma carga horária de
3.375 horas de Disciplinas Obrigatórias, 375 horas de Disciplinas Optativas e Atividades Dirigidas, com
significativa flexibilização, e mais 200 horas de Estágio Supervisionado Obrigatório, além de 30 horas
em atividades de Educação Física. Portanto totalizando uma carga horária de 3.980 horas, que poderão
ser integralizadas pelo estudante universitário no período mínimo de até 4,5 anos e no máximo de 8 anos
(16P.n.d).

A respeito do currículo implantado em 2006, no documento é afirmado que ele

oferecerá um maior número de disciplinas optativas, flexibilizando a matriz curricular e permitindo, através de orientação, que o estudante selecione aquelas disciplinas que mais atendam suas aptidões profissionais. Além de conteúdos teóricos mais aprofundados, a nova proposta permitirá que atividades desenvolvidas no decorrer do curso, como estágios extracurriculares, estágios de vivência, apresentações de trabalhos científicos em congressos ou seminários, entre outras, possam ser contabilizadas, ao final de cada atividade, gerando conceito e carga horária (17P.n.d).

Para a implementação desse projeto e adaptações que se fizessem necessárias, a proposição previa contar com a efetiva integração dos diversos departamentos acadêmicos responsáveis, direta ou indiretamente, pelo Curso de Agronomia da instituição, com tutela e regime de monitoramento coletivo que deve perpassar pelo Departamento de Agronomia.

O PPC atual não se encontra disponibilizado no site da instituição, nem nos endereços eletrônicos das duas 
Unidades Acadêmicas ofertantes do Curso de Agronomia. Conseguimos uma versão digital, a partir do contato direto que realizamos com a Secretaria da Coordenação do Curso que, na ocasião, nos informou que o mesmo se encontra em fase de revisão, "razão pela qual não está na página da Universidade", entretanto não deu previsão sobre quando seria finalizada e disponibilizada sua nova versão.

A detecção da frequência das palavras no documento, através da implementação de um algoritmo, permitiu visualizar alguns aspectos, de caráter preliminar, importantes para a construção da análise da proposta, conforme passamos a comentar. A palavra "humano" e suas derivações é citada apenas quatro vezes em todo o documento; "educação", apenas duas; por outro lado a expressão "técnica" e suas derivações (tecnologia, tecnólogo, tecnológico etc.) aparecem 68 vezes ao longo do texto; a expressão "agronegócio" é citada por treze vezes. Ambiente e sustentabilidade, e suas derivações, aparecem 45 e 26 vezes, respectivamente. Isto remete a refletir sobre a qual concepção de ambiente a proposição de curso se refere e, diante dela, de que forma define as abordagens que serão estabelecidas com os estudantes durante seu processo formativo.

A pequena frequência de aparição dos termos vinculados à perspectiva do "humano" e até mesmo da palavra "educação", aliada à elevada frequência da expressão "técnica" e derivações, e até mesmo "ambiente" e "sustentabilidade", permitem supor que as questões ambientais são tratadas no documento, porém marcadas por uma tradição naturalista que nega, ou minimiza, uma abordagem socioambiental, a qual levaria em conta "as relações de interação permanente entre a vida humana social e a vida biológica da natureza", conforme Carvalho (2006, p. 37). A análise temática do documento e entrevistas elucidaram com maior propriedade esta constatação feita a partir da análise da frequência de aparição das palavras no documento.

A expressão "Educação Ambiental” em si, não é citada nenhuma vez em todo o documento analisado. Assim, o PPC não apresenta, de forma explícita, nenhuma concepção de EA. Por outro lado, cumpre ponderar sobre o risco que pode significar o entendimento de que as questões referentes à Educação se acham suficientemente esclarecidas. Neste sentido, e conforme alertam Cavalari et al. (2006, p. 144).

\footnotetext{
Ao intencionalizar sua prática, ou seja, ao dar uma significação conceitual e valorativa para sua ação, o educador o faz a partir de determinadas ideias, crenças, valores, ideologias, conhecimentos e saberes, vale dizer, a partir de determinadas concepções. A intencionalização da prática pedagógica se realiza, portanto, a partir de concepções. Tais concepções, no entanto, nem sempre se expressam de maneira clara e transparente.
}

Desta maneira, compreendendo que as concepções de EA nem sempre poderiam estar suficientemente explicitadas, buscamos valorizar nesta análise as concepções de EA implícitas, a partir dos elementos ou indícios evidenciados no documento.

Das leituras do PPC e do conteúdo das entrevistas realizadas, sua análise por categorização temática possibilitou inferir a emergência de fortes indícios de uma concepção de EA conservadora, "naturalizada" que, conforme define Carvalho (2006, p. 35), tende a ver a natureza como o "mundo da ordem biológica", essencialmente boa, equilibrada, estável, autônoma e independente da interação com o mundo cultural humano, personificada em algumas passagens unicamente no próprio agrônomo, cuja presença aparece como a "chave" para a solução ou geração dos problemas. O depoimento a seguir ilustra esta situação: “Eu acho que é a principal profissão que tem que valorizar a educação ambiental e colocar em prática, porque é o profissional que atua diretamente na resolução de alguns desses problemas e também na geração deles” (88EA.c.e2).

Nesse contexto ainda, o material analisado atribui a enorme responsabilidade ao processo formativo, o qual deve preparar as pessoas, no caso os agrônomos, educando-os para entender as relações entre os elementos 
que compõem o ambiente.

A análise de conteúdo do PPC e das entrevistas permitiu abstrair que a percepção de ambiente, enfatizada no entendimento das relações entre os elementos que o compõem, parece dissociada da perspectiva humana, não levando em conta os aspectos de natureza também social, política, econômica e cultural, que compõem o ambiente na sua concepção mais ampla. Na Entrevista 1, a EA foi explicada como "a noção de como o ambiente funciona como um todo e as funções dos diferentes elementos nesse ambiente", e ressaltada a necessidade da pessoa "ser educada para entender essas relações" (71EA.E.c.t.e1). Em relação à Entrevista 2, igualmente à Entrevista 1, a mesma traz uma concepção conservadora, ecológica, onde a perspectiva de sustentabilidade surge, mas com ênfase nos aspectos da degradação dos recursos naturais e seus efeitos sobre a biodiversidade. Nela, a EA é compreendida como "uma área muito importante, que deve ser vista com cuidado, principalmente na atualidade onde acontece a degradação de vários recursos naturais, como o solo, como a água, e isso acarreta principalmente na condição de vida da gente e de toda biodiversidade do planeta. A gente tem que se preocupar, principalmente por conta que alguns desses recursos são finitos" (4EA.E.c.emas.e2).

Também a descrição do perfil do egresso reforça esta perspectiva conservadora de visão em relação às questões ambientais e sua relação com os agrônomos. O trato desta questão sempre remete a uma abordagem de "proteção à natureza", de forma superficial, não levando em conta o ser humano como parte dela, ou seja, dissocia ambiente e ser humano, ao desconsiderar as questões de natureza social, política e cultural. Conforme as passagens da entrevista, laconicamente se afirma que "os agrônomos deveriam ser pessoas extremamente educadas ambientalmente" (72E.e1) sem, entretanto, caracterizar com clareza que dimensões do ambiente estão sendo consideradas.

Tal perspectiva é reforçada pelo tratamento das questões de natureza ambiental, a priori compreendidas pelos entrevistados como se fossem práticas de EA, porém destituídas de uma abordagem mais complexa, que considere todas as dimensões que envolvem os problemas ambientais. Os recortes a seguir, que poderiam ser categorizados como exercício de interdisciplinaridade, característico da EA, terminam restritos à explicação dos problemas ambientais, pela consideração apenas dos fenômenos naturais, conforme foi destacado nas entrevistas realizadas:

Por que é que a gente hoje tem mais cheias em rios e tudo? Por conta de solos compactados e por conta de mais enxurrada que desce para o rio de uma vez só, ao invés da água infiltrar pelo solo, ela escoa pela superfície e enche o rio muito mais rápido. Em contrapartida, se ela infiltrasse com um solo mais original, mais preservado, o solo funciona como uma espécie de esponja que vai manter aquele rio perene por mais tempo, ou seja, você evita a enxurrada imediata, e mantém o rio perene por mais tempo, é tudo o que se quer, não é? E hoje em dia é tudo que não ocorre. Hoje em dia o solo absorve menos água, retém menos água, a enxurrada é maior, causa cheia na parte mais baixa do rio e o rio seca mais rápido, porque não tem aquela 'esponja' que vai alimentando aquele processo, então eu toco muito nesse assunto, mas na aula de solos, eu imagino que outros professores também façam isso (80EA.c.i.e1).

Eu não só comento o solo como um meio ali da produção, mas também o solo com a importância para o meio ambiente, qual a função do solo no meio ambiente. Eu toco nesse ponto várias vezes, que está dentro, de certa forma, de uma educação ambiental (79EA.c.i.e1).

A parte inicial do PPC, quando trata de aspectos de ordem mais geral sobre a concepção e funcionamento da proposta, delimita a integração dos diversos departamentos acadêmicos envolvidos com o curso, na promoção das adaptações que se fizerem necessárias, inclusive com processos de avaliação periódica junto aos docentes, discentes e outros fóruns:

A implementação desse projeto e as devidas adaptações que se fizerem necessárias ao longo do tempo, 
haverá de contar com a efetiva integração dos diversos departamentos acadêmicos responsáveis, direta ou indiretamente, pelo Curso de Agronomia. Nesse contexto, a tutela e o regime de monitoramento coletivo deverá perpassar pelo Departamento de Agronomia [...] que, para tanto, desenvolverá a implantação de auto-avaliações periódicas do Curso junto aos docentes, discentes e nos fóruns específicos de deliberação universitária (19P.n.i.d).

Entretanto, embora a parte inicial, que apresenta as generalidades conceituais do PPC, trate das perspectivas de interdisciplinaridade e de considerações de caráter socioambiental, as ementas das disciplinas apresentadas no documento, bem como o conteúdo das entrevistas realizadas não evidenciaram a presença dessas duas características. Já existe inclusive um movimento dos estudantes que têm procurado a coordenação do curso, demandando ênfase na abordagem de questões que envolvem a EA, conforme recorte da Entrevista 2:

Eu acredito que isso sempre permeou no Curso de Agronomia e agora, a própria demanda dos estudantes, [...] eu sinto que eles pedem mais disciplinas que abordem agroecologia, sustentabilidade, então eles têm cobrado a gente e eu acredito que essa cobrança também seja direta para cada professor, não é? Então vai forçar o professor a abordar essa questão com mais ênfase (94EA.emas.i.e2).

A compreensão sobre EA que aparece no PPC e entrevistas pode ser classificada como conservadora e é reforçada por uma visão utilitarista em relação à natureza, conforme recorte a seguir apresentado, que nos remete à reflexão de Grings (2009, p. 44) que, ao exacerbar o material, a abordagem utilitarista coloca o homem, no caso o agrônomo, no papel de "moderno criador dos mecanismos voltados ao alcance do sucesso e lucro". Aspecto revelado na entrevista, qual seja:

Afinal de contas, o que a gente faz como agrônomo, no fundo é manipular a natureza, porque você está plantando, você está fazendo com que a natureza aja a seu favor, e quanto mais isso está integrado com o ambiente, impactando o mínimo possível, melhor vai ser para o próprio ambiente e para o produto que você está gerando (73EA.E.u.emas.e1).

É importante aqui destacar que o atual PPC foi elaborado a partir da crítica ao anterior, cuja estrutura trazia “uma preocupação em fortalecer as áreas de Engenharia e Ciências Humanas" (9P.v.s.d), que terminou sendo associada a uma série de problemas, tais como: longa duração do curso, evasão, baixas notas nos exames de avaliação nacional. Os trechos a seguir, destacados do PPC analisado revelam este entendimento: "Houve uma preocupação em fortalecer as áreas de Engenharia e Ciências Humanas. Como resultado, o Curso de Agronomia [...] passou a ter uma duração mínima de cinco anos e meio e onze períodos letivos, com 4.475 horas, sendo considerado um dos mais longos cursos de Agronomia do País" (9P.v.s.d); e,

Naquela proposta pedagógica, por apresentar um excessivo número de disciplinas, que compartimentalizavam o conhecimento das áreas, levando, muitas vezes, à repetição de conteúdos de maneira desnecessária, constatou-se a falta de melhor integração entre as disciplinas de formação básica e as do ciclo profissional, tornando o curso demasiadamente longo e desarticulado. Esta realidade, possivelmente, vem contribuindo para o aumento das repetências e, como consequência, a elevação do índice anual de evasões dos discentes (10P.v.d).

É curioso quando se atribuem ao PPC anterior todos os problemas anteriormente listados, para justificar a necessidade da sua reformulação, visando o atendimento das aspirações pessoais dos que se interessam pela profissão, mas também da sociedade brasileira. O PPC reformulado parece não cumprir este sentido social na sua acepção mais ampla, quando privilegia uma abordagem tecnicista, fortemente direcionada ao agronegócio, com notável fragmentação do conhecimento, dedicando apenas 6,4\% da carga horária de Componentes Obrigatórias do Curso (3.375 horas), às cinco disciplinas agrupadas na categoria "Desenvolvimento Rural”, a saber: Princípios de Sociologia Rural (30h), Economia Rural (60h), Administração e Planejamento Rural (60h), 
Legislação e Política Agrária (45h) e Extensão Rural (60h) (31P.n.s.d).

Além disto, dentre os componentes optativos não existe, no PPC analisado, a disponibilidade de nenhuma disciplina na categoria "Desenvolvimento Rural", nem mesmo na categoria "Meio Ambiente" que aparece no conjunto de categorias criadas na proposta, igualmente sem nenhuma disciplina ali agrupada como possibilidade para os alunos cursarem, mesmo que quisessem se aprofundar um pouco mais nessas abordagens.

Aqui cabe também comentar que a reserva de um espaço para o agrupamento dos eventuais componentes curriculares específicos para tratar de questões ambientais, além destes nem existirem, conforme já foi comentado, não se coaduna com aquilo que prevê a Política Nacional de Educação Ambiental (Lei 9.795, de 27/04/1999), que dispõe que a EA, inclusive nos cursos de graduação, deve ser desenvolvida como uma prática educativa integrada, contínua, permanente, transversal e interdisciplinar, mas não como disciplina específica incluída nos currículos escolares (Brasil 1999).

A interdisciplinaridade da EA no Curso de Agronomia foi registrada nas duas entrevistas que compõem esta pesquisa, entretanto os entrevistados pareceram desconhecer isto como recomendação, do ponto de vista que tentam se justificar pela inexistência de uma disciplina específica: "a educação ambiental eu creio, pelo que eu me lembro aqui da grade, que eu imagino, que você vai conferir isso na grade lá, não tem nenhuma disciplina especificamente sobre isso não" (75EA.c.i.e1), ou ainda na Entrevista 2: "a gente, embora não tenha ainda uma disciplina específica de educação ambiental, mas ela está contemplada em diversas disciplinas” (87EA.i.e2).

O componente curricular "Agroecologia e Fitogeografia" (60 horas) foi mencionado nas duas entrevistas como o mais ligado à abordagem sobre o meio ambiente e à EA: "A educação ambiental é tratada dentro dos próprios programas, e uma ou outra mais ligada a meio ambiente, como é Agroecologia" (77EA.i.e1).

Os achados deste estudo envolvendo o Curso de Agronomia da instituição estudada coincidem com o realizado por Grings (2009), no âmbito da UFRGS e UFSM que revelou, apesar da crescente preocupação com a EA em nível governamental e a consciência mais aguçada quanto à importância do tema na formação profissional dos agrônomos, ainda ser incipiente o espaço da EA nos PPC e Currículos dos Cursos de Agronomia, que mantêm estruturas curriculares tradicionais, mesmo a despeito do esforço de alguns professores na inserção da EA nos PPC, nas estruturas curriculares, nas práticas educativas e nos seus processos de formação continuada, feitas de forma contextualizada e comprometida com a sociedade.

Carvalho (2006, p. 163), tratando sobre educação e cidadania também destaca a importância de uma educação crítica que forneça elementos para a formação de sujeitos capazes de se posicionarem em torno das questões ambientais:

\footnotetext{
Do ponto de vista de sua dimensão político-pedagógica, a EA poderia ser definida, lato sensu, como uma educação crítica voltada para a cidadania. Uma cidadania expandida, que inclui como objeto de direitos a integridade dos bens naturais não renováveis, o caráter público e a igualdade na gestão daqueles bens naturais dos quais depende a existência humana. Neste sentido, uma EA crítica deveria fornecer os elementos para a formação de um sujeito capaz tanto de identificar a dimensão conflituosa das relações sociais que se expressam em torno da questão ambiental quanto de posicionar-se diante desta (Carvalho 2006, p. 163).
}

Pois bem, o PPC analisado evidencia que a valorização da perspectiva cidadã na estrutura do Curso de Agronomia estudado, tão logo completou seu primeiro ciclo de formação, deu lugar a novas discussões, já no início dos anos 2000, apoiando-se, para tanto, em diversas críticas ao currículo implementado, tais como: a rigidez de um currículo mínimo e a duração mínima de cinco anos e meio, dentre outras, tendo como resultante que o Curso oferecido pela instituição estaria caracterizado pela "existência de uma arcaica grade curricular, 
rígida e de longa duração" (11P.v.d).

Finalmente, dado o Curso de Agronomia haver alcançado três conceitos C e um D, nos eventos do Exame Nacional de Cursos (ENC), realizados entre 2000 e 2003 para cumprimento da Lei no 9.131/95, isto é apresentado no PPC analisado como mais uma justificativa que reforça "sobremaneira as necessidades de atualização e flexibilização do Curso de Agronomia com a adoção de uma nova matriz curricular, bem mais flexível e menos longa" (13P.v.d). Aqui cabe esclarecer que, segundo Rothen e Barreyro (2011), nos ENC a indicação do resultado do desempenho dos estudantes se dava mediante cinco conceitos simplificados (A, B, C, D, E), diferentemente do atual ENADE, onde a avaliação de desempenho dos alunos de cada curso é expressa por meio de conceitos que variam de 1 (pior desempenho) a 5 (melhor desempenho), conforme destacam Schlickmann et al. (2008).

A análise realizada possibilitou perceber que as abordagens vinculadas aos aspectos sociais no PPC estão circunscritas à parte inicial do documento, a qual representa $1 / 4$ do seu conteúdo. Desta maneira, no perfil do egresso, por exemplo, delimita que a proposta "visa principalmente consolidar o perfil do Engenheiro Agrônomo egresso como apto a participar na sociedade civil, sendo ator proativo do desenvolvimento do segmento agrário na atual conjuntura da nação brasileira" (18E.s.d), contemplando o graduando com uma "formação generalista para sua participação social na história da sociedade civil, com a prática equilibrada da cidadania e de seu exercício profissional conforme as exigências e avanços da sociedade civil organizada e do mercado de trabalho" (22E.s.d).

Desta maneira, na sua parte mais geral, em que pesem as ressalvas feitas ao PPC anterior, cujo viés mais humanista teria resultado na série de problemas já relatados e que motivaram a concepção de uma nova proposta curricular, o atual PPC estabelece como finalidade para o curso, o desenvolvimento de conhecimentos e processos que guardem relação com o equilíbrio ambiental, considerando as perspectivas regionais, e ainda os aspectos de natureza histórica e sociais. Dentre os objetivos específicos do curso, o primeiro deles, conforme o documento analisado, é:

Desenvolver conhecimentos científicos para o estabelecimento de tecnologias socialmente justas, para o desenvolvimento de processos produtivos que imitem ou respeitem o equilíbrio dos ecossistemas naturais do País, mais particularmente do Nordeste. Propor modificações e/ou transformações nos sistemas de produção nordestinos, a partir do conhecimento dos ecossistemas, e do entendimento da formação histórica e das características atuais, no que tange à posse e uso da terra, às relações de trabalho e à base técnica (21E.s.emas.r.d).

Por outro lado, além do que é tratado na parte inicial do PPC, referente às perspectivas sociais e políticas que devem ser levadas em conta nos processos de EA, na apresentação das ementas dos componentes curriculares, estas abordagens são encontradas exclusivamente nos componentes obrigatórios das áreas de ciências humanas. As ementas de todos os demais componentes se restringem a abordagens teóricas ou práticas, fragmentadas, que não dialogam entre si, com forte viés tecnicista e foco no agronegócio, conforme evidenciam os seguintes recortes do PPC: "Capacitar o aluno a desempenhar atividades de manejo das plantas daninhas através do conhecimento da sua biologia e ecologia" (40EA.t.emas.d); "Identificar fatores limitantes quanto ao cultivo do solo em diferentes ambientes. Definir as opções de manejo adequado conforme as características de cada solo; Possibilitar o conhecimento das principais classes de solos do Nordeste e do Brasil e suas potencialidades para o uso agrícola" (41EA.t.r.d); “O aluno deverá ser capaz, de interpretar análises de solo e, a partir destas, recomendar as quantidades de corretivos e adubos para cada cultura de modo a atender a demanda nutricional 
e a segurança ambiental" (49EA.t.emas.d); "Desenvolver conhecimentos sobre os elementos essenciais para o entendimento das relações entre planta, ambiente natural. Qualificar para a utilização das recomendações tecnológicas necessárias ao manejo adequado das culturas alimentícias" (54EA.t.d); "Proporcionar ao estudante entendimento da importância de associações positivas e negativas entre plantas e microrganismos na sustentabilidade agrícola" (68EA.t.c.d); e, "Capacitar os discentes para a classificação dos solos quanto à salinidade e sodicidade, com o entendimento das propriedades desses tipos específicos de solos. Habilitá-los para o manejo de solos afetados por sais, seguindo técnicas que possibilitem melhores resultados agrícolas e ambientais" (70EA.t.d).

A respeito da ênfase no agronegócio, já na parte inicial do PPC, o documento destaca sua importância, aspecto que é reforçado nas entrevistas, conforme seguem: "O Brasil é atualmente o terceiro maior exportador mundial de produtos agrícolas e agora compete no mercado global com Estados Unidos, União Europeia e Austrália. No ano passado, o agronegócio respondeu por 30\% do Produto Interno Bruto (PIB) brasileiro, gerando 37\% dos empregos nacionais e representando 40\% de todas suas exportações” (28E.a.d); e,

\begin{abstract}
O nosso aluno hoje aqui é, eu diria que é quase 100\% da Zona da Mata, 100\%, não tem nenhum aluno de fora da Zona da Mata, não tem nenhum aluno do Agreste, então é tudo daqui, [...] Região Metropolitana e Zona da Mata [...]. Este é o público que vem para cá hoje, aí você muda muita coisa na universidade, por exemplo, que culturas a gente tem na zona da mata? Cana, tá certo? Aí a gente vem com várias perguntas: cana é a solução do mundo hoje? é o futuro? não sei, aqui para a região também não sei, vai migrar para outra cultura? Também não sei, mas é um público que está acostumado a ver cana, muitos deles chegam aqui querendo ser agrônomos canavieiros, e a gente não tem mais aquele aluno que vem do sertão (83E.a.e1).
\end{abstract}

O conteúdo das entrevistas realizadas parece reforçar a ênfase tecnicista fortemente presente também no PPC analisado. Neste sentido, cumpre chamar atenção para o sentido diverso daquele que prevê a literatura atualizada no que tange à EA na formação superior, onde a visão complexa do meio ambiente, a natureza integrando uma rede de relações naturais, sociais e culturais, de acordo com Carvalho (2006); a perspectiva de construção de uma sociedade ecologicamente prudente, socialmente justa, culturalmente diversa, atuante do ponto de vista político, conforme Layrargues (2012), precisam fazer parte da formação profissional, notadamente dos engenheiros agrônomos, conforme têm alertado também Souza (2006), Grings (2009), Araújo e Oliveira (2015), dentre outros autores. O que não se verifica no PPC e entrevistas analisadas.

Também foi possível inferir que o enfoque regional não é apresentado com grande visibilidade no PPC analisado, aparecendo em apenas cinco unidades de registro, uma na parte que trata de características gerais do documento (21E.s.emas.d) e as demais sendo mencionadas nas apresentações de ementas de alguns componentes curriculares do ciclo profissionalizante, tais como: Floricultura, Plantas Ornamentais e Paisagismo (50EA.r.t.emas.d), Fruticultura (51EA.r.d), Manejo de Solos no Semi-Árido (65EA.r.emas.d) e Ciência do Solo (41EA.t.r.d).

Cumpre destacar que a equipe que elaborou o PPC não teve nenhum representante das unidades acadêmicas localizadas no interior do Estado. Igualmente, não há nenhuma referência no documento analisado que relacione as adequações da proposta considerando as diferenças existentes entre as três regiões do Estado abrangidas pelo PPC analisado, embora o mesmo se trate de uma proposta construída para atender às três unidades acadêmicas da instituição que oferecem o curso (localizadas na capital e em dois municípios situados em regiões distintas do Estado, do ponto de vista edafo-climático, conforme já mencionamos) (1P.n.d).

O texto do PPC atual admite que o mesmo cumpre as diretrizes curriculares nacionais, dado que a 
aglutinação de disciplinas para composição da nova matriz curricular considerou três núcleos distintos de conteúdos: Básicos, Profissionais Essenciais e Profissionais Específicos, e são ministradas visando atender o interesse do processo pedagógico e a legislação federal vigente: Decreto n ${ }^{\circ}$ 23.196, de 12/12/1933 (Brasil 1933), a Lei no 5.194, datada de 24/12/1966 (Brasil 1966) e a Resolução no 218, do Conselho Federal de Engenharia, Arquitetura e Agronomia (Confea) de 29 de junho de 1973 (Confea 1973).

A respeito dessas legislações, convém destacar que o Decreto 23.196/1933 (Brasil 1933), da era do Presidente Getúlio Vargas, que regula o exercício da profissão agronômica e dá outras providências, não trata nada sobre EA, abordando apenas sobre os aspectos legais do exercício da profissão. Igualmente a Lei no 5.194/1966 (Brasil 1966), que regula o exercício das profissões de Engenheiro, Arquiteto e Engenheiro-Agrônomo e dá outras providências, e a Resolução no 218/1973 (Confea 1973), que discrimina as atividades das diferentes modalidades profissionais da Engenharia, Arquitetura e Agronomia, também não tratam de EA. Esta última até cita duas vezes a palavra "ambiente", porém relacionando-o especificamente ao controle sanitário, higiene e conforto, nas competências dos Engenheiros Sanitaristas.

Reforçando o entendimento da supremacia das questões de natureza técnica sobre aquelas de natureza social na abordagem de ambiente, já na delimitação do objetivo geral do curso, conforme disposto no PPC, as questões de natureza técnica precedem as de natureza social e política e, neste sentido convém lembrar que Bardin (1994) evidencia a pertinência de considerar a ordem de aparição das unidades de registro nas entrevistas ou relatos, conferindo significado de maior importância no quadro de inferências para aqueles elementos que precedam outros (Bardin 1994, p. 138).

O Curso de Agronomia [...] tem como objetivo ministrar o ensino das Ciências Agrárias em nível superior, graduando Engenheiros Agrônomos capazes de promover, orientar e administrar a utilização dos fatores de produção visando racionalizar a produção vegetal e animal, planejar, pesquisar e aplicar técnicas, métodos e processos adequados à solução de problemas agrícolas e pastoris. Considerando genericamente também os aspectos sócio-econômicos, políticos, culturais e éticos, mas sempre visando o desenvolvimento agrário sustentável e preenchendo os requisitos previstos no Decreto $\mathrm{n}^{\circ} 23.196$, de 12/12/1933, a Lei no 5.194, datada de 24/12/1966, e a Resolução CONFEA n 218, de 29/06/1973, que juntas regem o exercício legal da profissão do Engenheiro Agrônomo no Brasil (20P.n.t.s.d, grifo nosso).

Finalizando são apresentadas as considerações finais e as referências utilizadas no presente estudo.

\section{CoNSIDERAÇÕES FINAIS}

A título de considerações finais podemos inferir que, embora não haja uma definição explícita da concepção de EA que norteia o documento, há fortes indícios da realização de processos de EA conservadora, que tratam dos temas ambientais de maneira desvinculada das variáveis de natureza social, cultural e política, com o ambiente e seus fenômenos sendo tratados de maneira fragmentada, privilegiando a abordagem mais técnica, característica reforçada no conteúdo das entrevistas realizadas no âmbito desta pesquisa.

Tal tendência traz como resultante uma formação cuja percepção limitada em relação aos aspectos que envolvem a realidade ambiental, do ponto de vista da complexidade, resulta em prejuízos para o exercício desses profissionais. Estes, muitas vezes, avaliam que suas atividades e proposições estão circunscritas à natureza técnica, abordagem alicerçada nos currículos mais tradicionais, vivenciados nos cursos de agronomia do país, não percebendo, ou mesmo desconsiderando, as diferentes variáveis que estão relacionadas aos processos de 
organização das atividades produtivas com as quais estão envolvidos. A EA, na perspectiva de formação de engenheiros agrônomos comprometidos com as questões da sustentabilidade torna-se atributo imprescindível a ser vivenciado nos cursos do país, não só devido ao impacto das atividades agrícolas sobre os recursos naturais, mas também dada a sua relação com os fatores de natureza socioeconômica.

Ademais, o mapeamento das concepções de EA nos componentes curriculares obrigatórios e optativos presentes no PPC analisado revelou que eles parecem não dialogar entre si, ficando as abordagens sobre os aspectos sociais restritas aos cinco componentes agrupados na categoria "Desenvolvimento Rural", quais sejam: Sociologia Rural, Economia Rural, Administração e Planejamento Rural, Legislação e Política Agrária, e Extensão Rural, que juntos totalizam 255 horas/aula, ou seja, apenas 6,4\% da carga horária total do curso. Além disto, unicamente o componente "Agroecologia e Fitogeografia" é referenciado nas entrevistas com aquele onde acontecem com mais ênfase os processos de EA no curso.

Em síntese, e com relação à EA sendo valorizada como ação educativa interdisciplinar, articuladora do conjunto de saberes, visando contribuir para a formação de atitudes e sensibilidades ambientais; a análise do documento e das entrevistas permitiu inferir que isto parece não acontecer. Todavia, o aprofundamento da pesquisa, com a delimitação de um universo para investigação da prática docente, por meio da observação participante nas aulas, poderá revelar, a partir da realidade concreta da sala de aula, local onde docente e discente interagem, que concepções de EA estão permeando a formação dos Engenheiros Agrônomos diplomados pela instituição.

\section{REFERÊNCIAS}

Araújo JBS e Oliveira PES. 2015. A educação ambiental na grade curricular do curso de Agronomia da UFS. Revista Sergipana de Educação Ambiental, 1(2):112-129.Disponível em: < http://www.seer.ufs.br/index. php/revisea/article/view/4447>. Acesso em 20 nov. 2015.

Araújo MLF. 2012a. A Educação ambiental no mundo e no Brasil: sementes plantadas. In: Oliveira G. Formando Educadores Socioambientais. Recife: Núcleo de Estudos em Formação Docente e Prática Pedagógica (NEFOPP), p. 4-20.

Araújo MLF. 2012b. O quefazer da Educação Ambiental crítico-humanizadora na formação inicial de professores de Biologia na universidade. Tese (Doutorado em Educação) - Recife: Universidade Federal de Pernambuco, 240f.

Bardin L. 1994. Análise de conteúdo. Lisboa: Edições 70.

Brasil. 1933. Decreto $\mathbf{n}^{\mathbf{o}}$ 23.196, de 12 de outubro de 1933. Regula o exercício da profissão agronômica e dá outras providências. Disponível em: < https://www.planalto.gov.br/ccivil_03/decreto/1930-1949/d23196.

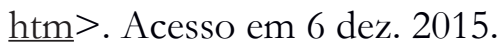

Brasil. 1966. Lei $\mathbf{n}^{\mathbf{0}}$ 5.194, de 24 de dezembro de 1966. Regula o exercício das profissões de Engenheiro, Arquiteto e Engenheiro-Agrônomo, e dá outras providências. Disponível em: < http://www.planalto.gov.br/ 
ccivil 03/Leis/L5194.htm>. Acesso em 6 dez. 2015.

Brasil. 1999. Lei n⿳0 9.795, de 27 de abril de 1999. Dispõe sobre a Educação Ambiental, institui a Política Nacional de Educação Ambiental e dá outras providências. Disponível em: < http://www.planalto.gov.br/ccivil_03/Leis/ L9795.htm>. Acesso em 1 nov. 2015.

Carvalho ICM. 2006. Educação ambiental: a formação do sujeito ecológico. 2 ed. São Paulo: Cortez.

Cavalari RMF, Santana LC e Carvalho LM. 2006. Concepções de educação e educação ambiental nos trabalhos do I EPEA. Pesquisa em Educação Ambiental, 1(1):141-173. Disponível em: < http://repositorio.unesp.br/ handle/11449/108277>. Acesso em 1 nov. 2015.

Confea. 1973. Resolução $\mathbf{n}^{\mathbf{0}} \mathbf{2 1 8}$, de 29 de junho de 1973. Discrimina atividades das diferentes modalidades profissionais da Engenharia, Arquitetura e Agronomia. Disponível em: < $\underline{\text { http://normativos.confea.org.br/ }}$ ementas/visualiza.asp?idEmenta=266>. Acesso em 6 dez. 2015.

Freire P. 2002. Pedagogia da autonomia: saberes necessários à prática educativa. 22 ed. Rio de Janeiro: Paz e Terra.

Gadotti M. 2001. Prefácio. In: Padilha PR. Planejamento dialógico: como construir o projeto político pedagógico da escola. 2 ed. São Paulo: Cortez; Instituto Paulo Freire (Guia da Escola Cidadã, v. 7).

Gandin D. 1999. Planejamento como prática educativa. São Paulo: Loyola.

Gil AC. 2009. Didática do ensino superior. 4. reimpr. São Paulo: Atlas.

Grings VT. 2009. Educação ambiental no ensino superior: estudo de caso no Curso de Agronomia. Tese (doutorado). Porto Alegre: Universidade Federal do Rio Grande do Sul. Programa de Pós-Graduação em Educação. Disponível em: < https://www.lume.ufrgs.br/bitstream/handle/10183/17246/000713414. pdf? sequence=1>. Acesso em 20 dez. 2015.

Layrargues PP.(Org.). 2004. Identidades da educação ambiental brasileira. Brasília: Ministério do Meio Ambiente. Disponível em: <http://www.mma.gov.br/estruturas/educamb/ arquivos/livro ieab.pdf>. Acesso em 15 dez. 2015.

Layrargues PP. 2012. Para que a Educação Ambiental encontre a Educação. In: Loureiro CFB. Trajetória e fundamentos da educação ambiental. 4 ed. São Paulo: Cortez, p. 13-21.

Padilha PR. 2001. Planejamento dialógico: como construir o projeto políticopedagógico da escola. 2 ed. São Paulo: Cortez; Instituto Paulo Freire (Guia da Escola Cidadã, v. 7).

PPC. 2006. PPC da instituição estudada.

Rothen JC; Barreyro GB. 2011. Avaliação da educação superior no segundo governo Lula: Provão II ou a reedição de velhas práticas. Educação \& Sociedade, Campinas, v. 32, n. 114, jan./mar. Disponível em: < http://www. scielo.br/pdf/es/v32n114/a02v32n114.pdf>. Acesso em: 26 out. 2017. 
Schlickmann R; Roczanski CRM; Azevedo P. 2008. Provão X ENADE: uma análise comparativa. Repositório

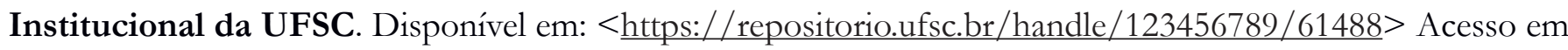
26 out. 2017.

Souza SER. 2006. A inserção da Educação Ambiental no Currículo do Curso de Agronomia: um estudo de caso na UFSM. Dissertação de Mestrado do Programa de Pós-graduação em Educação. Santa Maria - RS: Universidade Federal de Santa Maria. Santa Maria.

Veiga IPA. (Org.). 1995. Projeto político-pedagógico da escola: uma construção possível. Campinas, SP: Papirus. 